\title{
An Evaluation of the Luminous-Transmittance Require- ments for Railroad-Signal Glassware in Terms of Standard Source $A$ of the International Commission on Illumination
}

\author{
Francis C. Breckenridge
}

\begin{abstract}
As an extension of Research Paper 1688, an estimate has been made of the transmittance for illuminant A of signal glassware having the minimum transmittance acceptable under the specifications of the Signal Section of the Association of American Railroads, which are formulated in terms of tests at $2,360^{\circ} \mathrm{K}$.
\end{abstract}

In connection with the preparation of the last Secretariat Report on Colors of Signal Lights [1] ${ }^{1}$ for the International Commission on Illumination, it was desired to include values for the minimum transmittance for railroad-signal glassware used in this country and to show these values for light sources of color temperature $2,850^{\circ} \mathrm{K}$ since the other countries had reported transmittance values for their glassware for lamps of that color temperature. The revision of the specifications for railroad-signal glassware, which is now being considered by the Signal Section of the Association of American Railroads (AAR), suggests that this information may now have a wider interest. A method for computing minimum transmittance at $2,850^{\circ} \mathrm{K}$ from the currently specified minimum-transmittance values is accordingly described below.

AAR Specifications 59-39 and 69-48 control the transmittance of railroad-signal glasses by limits assigned on a scale known as the $T_{\mathrm{AAR}}$ scale. This scale (actually six scales, one for each of six signal colors) was established by a procedure described in RP1209 [2]. It is defined in terms of six luminoustransmittance values for a source of $2,360^{\circ} \mathrm{K}$, each of these values being applicable to glasses having chromaticity characteristics similar to the filters used for one of the railroad-signal colors. The transmittance values for the six signal colors corresponding to $T_{\mathrm{AAR}}=100$ are listed in table $6 \mathrm{RP} 1209$ [2], and in table 1 in RP1688 [3]. In practice, the $T_{\text {AAR }}$ values of glasses submitted for inspection are determined by finding the ratio of the transmittance of the glass being tested to the transmittance of one of the "limit" filters and multiplying this ratio by the $T_{\mathrm{AAR}}$ value of the limit filter. The transmittance values for the primary-standard "limit" filters for sources of color temperature $1,900^{\circ} \mathrm{K}$,

\footnotetext{
1 Figures in brackets indicate the literature references at the end of this paper.
}

$2,360^{\circ} \mathrm{K}$, and $2,848^{\circ} \mathrm{K}^{2}$ have been published, together with their $T_{\mathrm{AAR}}$ values at $2,360^{\circ} \mathrm{K}$, in table 4 of RP1688 [3].

The inspection of signal glassware is carried out at color temperature $2,360^{\circ} \mathrm{K},{ }^{3}$ but the glassware is used in service with sources ranging from $1,900^{\circ} \mathrm{K}$ to $2,850^{\circ} \mathrm{K}$. For a source of color temperature $2,360^{\circ} \mathrm{K}$, the minimum acceptable transmittance is readily computed from the simple proportion:

$$
(T)_{\min } /(T)_{\mathrm{std}}=\left(T_{\mathrm{AAR}}\right)_{\min } /\left(T_{\mathrm{AAR}}\right)_{\mathrm{std}},
$$

in which:

$(T)_{\min }=$ transmittance of glass of minimum acceptable $T_{\mathrm{AAR}}$,

$(T)_{\text {std }}=$ transmittance of standard filter at $2,360^{\circ} \mathrm{K}$

$\left(T_{\mathrm{AAR}}\right)_{\min }=T_{\mathrm{AAR}}$ stated in specification as minimum acceptable,

$\left(T_{\mathrm{AAR}}\right)_{\mathrm{std}}=T_{\mathrm{AAR}}$ value of standard filter.

This simple proportion does not give correct values of transmittance for sources of other temperatures since the ratio of the transmittance at one color temperature to that at another varies with the value of $T$ itself. This variation, however, is systematic and with respect to each type of glassware, it may, to a first degree of approximation, be considered as linear.

2 The numerical designations of color temperature used in RP1688 [3] were based upon $C_{2}=14,350$ micron degrees in Planck's formula. We here use the same designations in order to avoid confusion. The presently-accepted value of $\mathrm{C}_{2}$ is 14,380 micron degrees, and the corresponding values of color temperature are:

$$
\begin{array}{cc}
C_{2}=14,350 \text { micron degrees } & C_{2}=14,380 \text { micron degrees } \\
{ }^{\circ} K & \circ K \\
1,900 & 1,904 \\
2,360 & 2,365 \\
2,848 & 2,854
\end{array}
$$

In service there is considerable variation in color temperature for each type of source so that the approximate values $1,900^{\circ} \mathrm{K}, 2,350^{\circ} \mathrm{K}$, and $2,850^{\circ} \mathrm{K}$ may be used when the reference is to service conditions.

3 The latest draft for the revision of specification AAR 69-48 provides that inspection will be made at $2,854^{\circ} \mathrm{K}$. 
The desired transmittance values for $2,854^{\circ} \mathrm{K}$ were computed in accordance with the following assumptions:

(1) That for each type and color, the glassware in service has the same characteristics as the pale limit and transmission standard filters which should be true if it contains the same colorants in about the same proportions as the filters which control it;

(2) That the ratio $T_{2,848} / T_{2,360}$ is approximately a linear function of the transmittance.

Using the vaues of transmittance listed in table 4 RP1688 [3], the ratio $T_{2,848} / T_{2,360}$ was computed for each filter and these ratios were plotted as functions of the corresponding $T_{\mathrm{AAR}}$ values at $2,360^{\circ} \mathrm{K}$ (see fig. 1). The value of minimum acceptable transmittance for a source at $2,848^{\circ} \mathrm{K}$ was then computed from the formula:
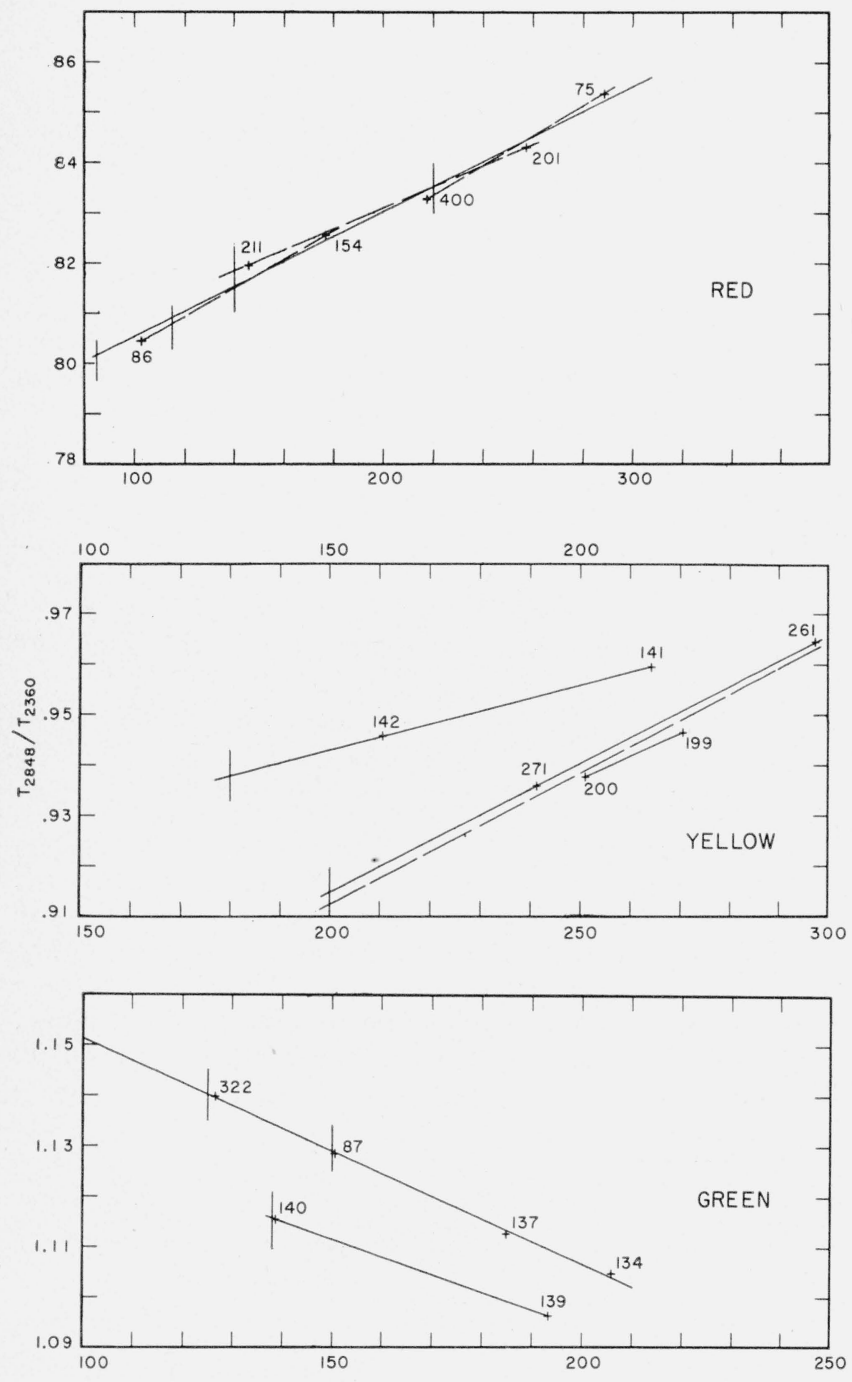

FIGURE 1. Each of the above figures shows the relation between the ratio $T_{2,848} / T_{2.360}$ and the $T_{\mathrm{AAR}}$ value for the primary standard filters of one color.

$\left(T_{2,848}\right)_{\min }=0.01\left(T_{\mathrm{AAR}}\right)_{\min } \times\left(T_{2,360}\right)_{\mathbf{1 0 0}} \times\left(T_{2,848} / T_{2,360}\right)_{\min }$

in which:

$\left(T_{2,848}\right)_{\min }=$ transmittance of glass of minimum acceptable transmittance for light of color temperature $2,848^{\circ} \mathrm{K}$,

$\left(T_{\mathrm{AAR}}\right)_{\min }=T_{\mathrm{AAR}}$ stated in specification as minimum acceptable,

$\left(T_{2,360}\right)_{100}=$ transmittance corresponding to 100 on $T_{\mathrm{AAR}}$ scale for light of color temperature $2,360^{\circ} \mathrm{K}$,

$\left(T_{2,848} / T_{2,360}\right)_{\min }=$ ratio of transmittances at minimum acceptable $T_{\text {AAR }}$ value, read from graph.
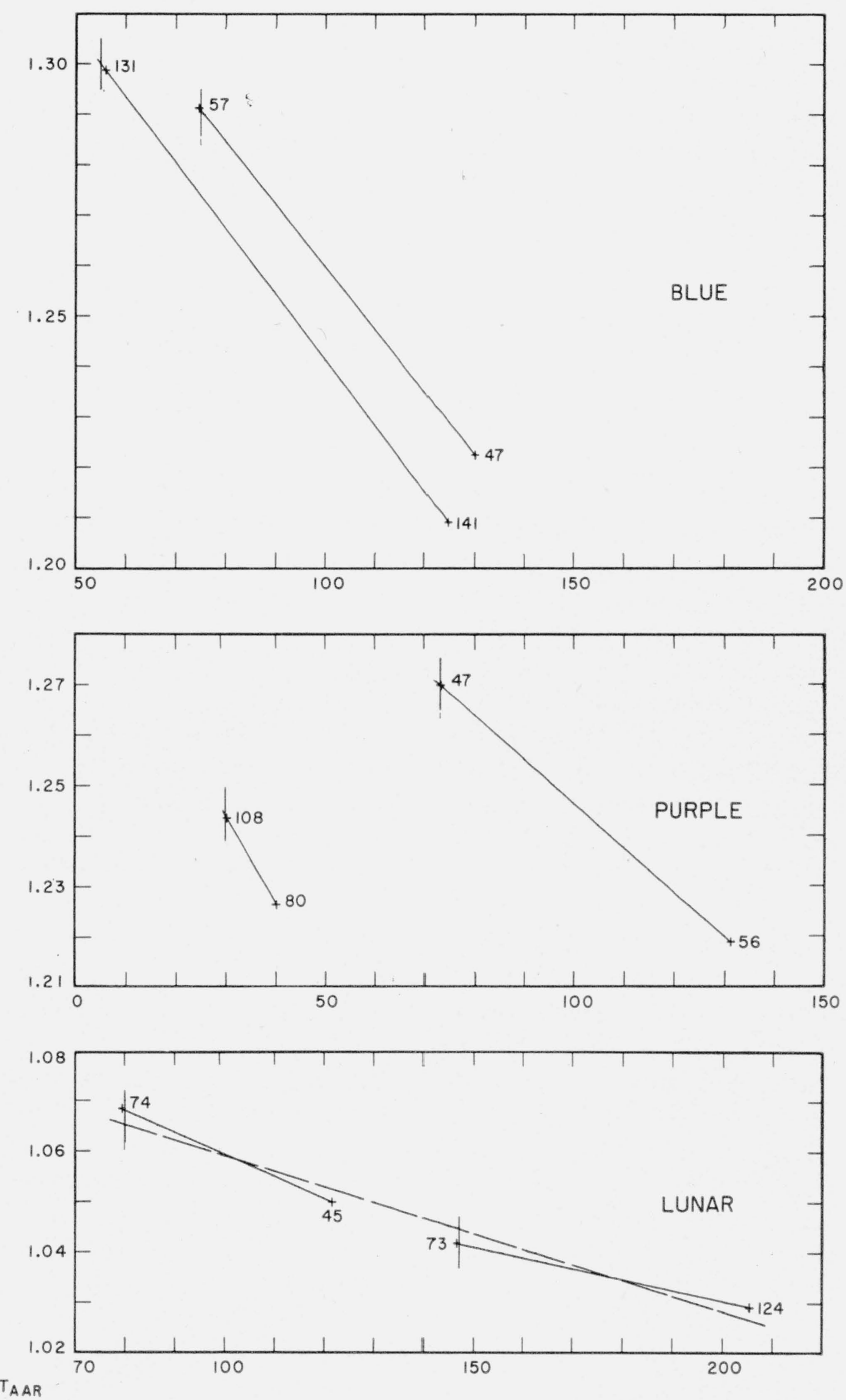

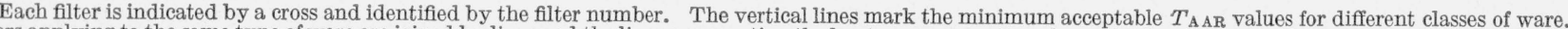

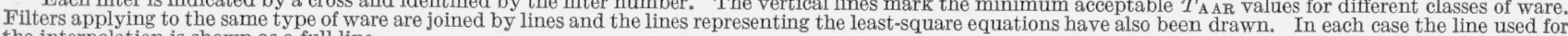
the interpolation is shown as a full line. 
TABLE 1. Minimum acceptable transmittance for light of $2,848^{\circ} \mathrm{K}$ for railroad signal glassware

\begin{tabular}{|c|c|c|c|c|c|c|}
\hline \multirow{3}{*}{ Kind of ware } & \multicolumn{2}{|c|}{ AAR filter numbers } & \multicolumn{4}{|c|}{ At minimum acceptable transmittance } \\
\hline & \multirow{2}{*}{$\begin{array}{c}\text { Pale } \\
\text { limits }\end{array}$} & \multirow{2}{*}{$\begin{array}{l}\text { Transmis- } \\
\text { sion } \\
\text { Standard }\end{array}$} & \multirow{2}{*}{$T_{\mathrm{AAR}}$} & \multicolumn{2}{|c|}{$T_{2,848} / T_{2,360}$} & \multirow{2}{*}{$T_{2,848}$} \\
\hline & & & & By graph & ByL.S.Eq. & \\
\hline \multirow{3}{*}{$\begin{array}{l}\text { Pressed ware, general. } \\
\text { Thin disks } \\
\text { Electric lanterns } \\
\text { Kerosene lanterns } \\
\text { Highway Crossing }\end{array}$} & \multicolumn{6}{|c|}{ Red glasses (for $T_{\mathrm{AAR}}=100, T_{2,360}=0.0690$ ) } \\
\hline & $\begin{array}{r}154 \\
154 \\
154 \\
201 \\
75\end{array}$ & $\begin{array}{r}86 \\
86 \\
86 \\
211 \\
400\end{array}$ & $\begin{array}{r}85 \\
115 \\
140 \\
140 \\
220\end{array}$ & $\begin{array}{r}0.7993 \\
.8079 \\
.8152 \\
.8185 \\
.8336\end{array}$ & $\begin{array}{l}\text { b } 0.8018 \\
\text { b. } 8092 \\
\text { b. } 8155 \\
\text { b. } 8155 \\
\text { b. } 8353\end{array}$ & $\begin{array}{l}0.0469 \\
.0641 \\
.0788 \\
.0788 \\
.1268\end{array}$ \\
\hline & \multicolumn{6}{|c|}{ Yellow glasses (for $T_{\mathrm{AAR}}=100, T_{2,360}=0.2474$ ) } \\
\hline \multirow[t]{2}{*}{$\begin{array}{l}\text { Nonheat resisting } \\
\text { Thin disks } \\
\text { Kerosene lanterns }\end{array}$} & $\begin{array}{l}141 \\
199 \\
261\end{array}$ & $\begin{array}{l}142 \\
200 \\
271\end{array}$ & 130 & $\begin{array}{r}\text { b0. } 9378 \\
- \text { b. } 9147\end{array}$ & $\begin{array}{l}-0 .-1 \\
-.9124\end{array}$ & $\begin{array}{r}0.301_{6} \\
.452_{6}\end{array}$ \\
\hline & \multicolumn{6}{|c|}{ Green glasses (for $T_{\mathrm{AAR}}=100, T_{2,380}=0.1186$ ) } \\
\hline \multirow[t]{2}{*}{$\begin{array}{l}\text { Nonheat resisting } \\
\text { Thin disks... } \\
\text { Kerosene lanterns }\end{array}$} & $\begin{array}{l}134 \\
139 \\
137\end{array}$ & $\begin{array}{r}87 \\
140 \\
322\end{array}$ & $\begin{array}{l}150 \\
138 \\
125\end{array}$ & $\begin{array}{r}1.1287 \\
\text { b1. } 1157 \\
1.1404\end{array}$ & $\begin{array}{r}\text { b1. } 1289 \\
\text { b1. } 1400\end{array}$ & $\begin{array}{r}0.2008 \\
.1826 \\
.1690\end{array}$ \\
\hline & \multicolumn{6}{|c|}{ Blue glasses (for $T_{\mathrm{AAR}}=100, T_{2,360}=0.0223$ ) } \\
\hline \multirow[t]{2}{*}{$\begin{array}{l}\text { Nonheat resisting } \\
\text { Kerosene lanterns }\end{array}$} & $\begin{array}{r}47 \\
141\end{array}$ & $\begin{array}{r}57 \\
131\end{array}$ & $\begin{array}{l}75 \\
55\end{array}$ & $\begin{array}{l}\text { b1. } 2907 \\
\text { b1. } 2987\end{array}$ & - n & $\begin{array}{r}0.0216 \\
.0159\end{array}$ \\
\hline & \multicolumn{6}{|c|}{ Purple glasses (for $T_{\mathrm{AAR}}=100, T_{2,360}=0.0129$ ) } \\
\hline \multirow[t]{2}{*}{$\begin{array}{l}\text { Kerosene illuminant. } \\
\text { Electric illuminant... }\end{array}$} & $\begin{array}{l}56 \\
80\end{array}$ & $\begin{array}{r}47 \\
108\end{array}$ & $\begin{array}{l}73 \\
30\end{array}$ & $\begin{array}{l}\text { b1. } 2698 \\
\text { b1. } 2438\end{array}$ & (n) & $\begin{array}{r}0.0120 \\
.0048\end{array}$ \\
\hline & & Lunar gla & es (for $T$ & $\mathrm{R}=100, T_{2,3}$ & $0=0.1895)$ & \\
\hline $\begin{array}{l}\text { Kerosene illuminant_- } \\
\text { Pressed_ware electric illuminant_- } \\
\text { Thin disks. }\end{array}$ & $\begin{array}{r}45 \\
124 \\
124\end{array}$ & $\begin{array}{l}74 \\
73 \\
73\end{array}$ & $\begin{array}{r}80 \\
147\end{array}$ & $\begin{array}{l}\text { b1. } 0680 \\
\text { b1. } 0416 \\
\end{array}$ & $\begin{array}{l}1.0651 \\
1.0445 \\
-\end{array}$ & $\begin{array}{r}0.162 \\
.290 \\
\hdashline-2\end{array}$ \\
\hline
\end{tabular}

a In RP1688 [3], these filters are called "light limit" and "dark limit" because these designations are used in the railroad specifications. "Light" refers to chromaticity, however, and the true dark limit is the $T_{\mathrm{AAR}}$ value, which makes tbe designations used above seem preferable.

b Used for computing $T_{2,848}$.

Table 1 summarizes the computations. All the basic numerical values were taken from tables 2 and 4 of RP1688 [3] and table 6 of RP1209 [2]. The values of the ratio $T_{2,848} / T_{2,360}$ were obtained by graphical interpolation, supplemented by least-square solutions in the case of the red glassware and two types of green glassware that appeared to have similar chromaticity characteristics. The graphs used for these interpolations are presented in figure 1.

In the belief that the least-square differences may be an indication of the reliability of our basic assumption that $T_{2,848} / T_{2,360}$ is a linear function of the transmittance, these differences have been computed, not only for the red and green cases just mentioned, but also for four of the yellow filters and the four lunar white filters. These differences are listed in table 2. In no case is the difference greater than
0.3 percent of the ratio. While this value is large in comparison with the probable errors for the transmittances of the standard filters, it is not significant from the standpoint of the signal glassware in service.

The values given in column 5 of table 2 may also be used to compute the approximate transmittance for light of color temperature $2,854^{\circ} \mathrm{K}$ of replica filters which have been certified for light of color temperature $2,365^{\circ} \mathrm{K}\left(2,360^{\circ} \mathrm{K}\right.$ for older certifications). It is only necessary to multiply the value given for $T_{2,848} / T_{2,360}$ corresponding to the primary standard by the certified transmittance of the replica at color temperature $2,365^{\circ} \mathrm{K}$ to obtain a value of transmittance for the replica at color temperature $2,854^{\circ} \mathrm{K}$ with an uncertainty which may be estimated from the values given in column 6 of the table. 
TABLE 2. Least-square solutions for groups of four or more related filters

\begin{tabular}{|c|c|c|c|c|c|}
\hline \multicolumn{6}{|c|}{$T_{2,848} / T_{2,360}=K+k T_{\mathrm{AAR}} / 100$} \\
\hline \multirow{2}{*}{$\begin{array}{l}\text { AAR } \\
\text { filter } \\
\text { number }\end{array}$} & \multicolumn{2}{|c|}{ Equation constants } & \multicolumn{2}{|c|}{$T_{2,848} / T_{2,360}$} & \multirow{2}{*}{$\underset{\substack{\text { Column } \\
\text { minus } \\
\text { column } 4}}{\Delta}$} \\
\hline & $K$ & $k$ & $\begin{array}{l}\text { From } \\
\text { measure- } \\
\text { ments }{ }^{1}\end{array}$ & $\begin{array}{l}\text { From } \\
\text { equation }\end{array}$ & \\
\hline 1 & 2 & 3 & 4 & 5 & 6 \\
\hline $\begin{array}{c}\text { Red } \\
75 \\
86 \\
154 \\
201 \\
211 \\
400\end{array}$ & $\begin{array}{c}+0.78071 \\
\\
\end{array}$ & $\begin{array}{r}+0.02482 \\
\\
\end{array}$ & $\begin{array}{r}0.8537 \\
.8045 \\
.8257 \\
.8430 \\
.8197 \\
.8329\end{array}$ & $\begin{array}{r}0.8522 \\
.8062 \\
.8246 \\
.8444 \\
.8168 \\
.8347\end{array}$ & $\begin{array}{r}-0.0015 \\
+.0017 \\
-.0011 \\
+.0014 \\
-.0029 \\
+.0018\end{array}$ \\
\hline $\begin{array}{l}\text { Yellow } \\
199 \\
200 \\
261 \\
271\end{array}$ & +.80878 & $\begin{array}{l}+.05180 \\
-\end{array}$ & $\begin{array}{l}.9465 \\
.9377 \\
.9643 \\
.9358\end{array}$ & $\begin{array}{l}.9489 \\
.9388 \\
.9628 \\
.9337\end{array}$ & $\begin{array}{r}-.0024 \\
-.0011 \\
+.0015 \\
+.0021\end{array}$ \\
\hline $\begin{array}{l}\text { Green } \\
87 \\
134 \\
137 \\
322\end{array}$ & $\begin{array}{c}+1.19562 \\
\end{array}$ & $\begin{array}{c}-.04446 \\
\end{array}$ & $\begin{array}{l}\text { 1. } 1284 \\
\text { 1. } 1048 \\
\text { 1. } 1126 \\
1.1398\end{array}$ & $\begin{array}{l}\text { 1. } 1287 \\
\text { 1. } 1041 \\
\text { 1. } 1134 \\
\text { 1. } 1393\end{array}$ & $\begin{array}{r}-.0003 \\
+.0007 \\
-.0008 \\
+.0005\end{array}$ \\
\hline $\begin{array}{l}\text { Lunar } \\
45 \\
73 \\
74 \\
124\end{array}$ & $\begin{array}{c}+1.08967 \\
\end{array}$ & $\begin{array}{l}-.03071 \\
\end{array}$ & $\begin{array}{l}1.0499 \\
1.0417 \\
1.0682 \\
1.0290\end{array}$ & $\begin{array}{l}1.0523 \\
1.0447 \\
1.0652 \\
1.0266\end{array}$ & $\begin{array}{r}-.0024 \\
-.0030 \\
+.0030 \\
+.0024\end{array}$ \\
\hline
\end{tabular}

1 For example, values in RP1688 [3].

\section{References}

[1] Proc. Intern. Comm. Illumination, Zurich, 13th Session, 1, sec. 1.3 .3 , p. 28 (1955).

[2] Kasson S. Gibson and Geraldine Walker Haupt, Standardization of the luminous-transmission scale used in the specification of railroad signal glasses, J. Research, NBS 22, 627 (1939) RP1209.

[3] Kasson S. Gibson, Geraldine Walker Haupt, and Harry J. Keegan, Specification of railroad signal colors and glasses, J. Research, NBS 36, 1 (1946) RP1688.

Washington, August 12, 1957. 